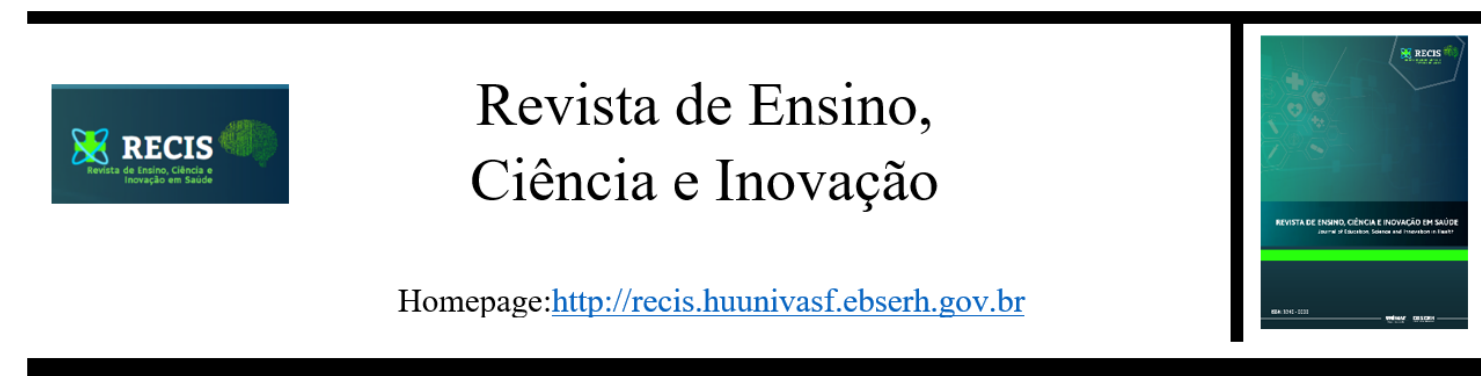

\title{
Distribuição Geográfica dos casos da COVID-19 no Município de Petrolina, Pernambuco, Brasil
}

\section{Geographic distribution of COVID-19 cases in the municipality of Petrolina, Pernambuco, Brazil}

\author{
Eliene Aparecida Cerqueira Marcos¹, Maria Eduarda Cunha dos Santos', \\ Juvenilson Sá de Andrade ${ }^{1}$, Bruna Del Vechio Koike ${ }^{1}$
}

\begin{abstract}
${ }^{1}$ Universidade Federal do Vale do São Francisco, Petrolina, Pernambuco, Brasil. Autor correspondente: elieneacmarcos@gmail.com
\end{abstract}

Artigo recebido em 05/10/2020 e aceito em 22/11/2020

\section{RESUMO}

A COVID-19 tem se mostrado uma doença amplamente difundida, tendo, assim, alcançado a escala de pandemia mundial. Sua distribuição se deu de forma não uniforme e foi modulada por diversos fatores. Em Petrolina - PE, tem-se observado a propagação do vírus desde o final do mês de março de 2020 com evolução crescente. O objetivo deste trabalho é observar como se deu a distribuição geográfica dos casos confirmados da COVID-19 em Petrolina - no período de 23 de março a 18 de julho de 2020. A análise foi feita a partir do monitoramento das informações sobre os casos confirmados na região, publicadas pela secretaria da saúde do município de Petrolina e, os dados sobre o estado e o país, divulgados pelo Ministério da Saúde. Observamos que este vírus foi introduzido na região por pessoas que chegaram de viagem do exterior no mês de março, nas regiões centrais de Petrolina, seguida de uma gradual crescente de casos confirmados da doença, espalhando-se para os bairros mais populosos. Com isso, vimos que a propagação é mais rápida em áreas populosas e com poucas medidas de precaução. Inúmeros desafios precisam ser superados frente ao novo coronavírus. Até o momento, sabe-se que o distanciamento social e equipamentos de proteção individual mitigam a disseminação do vírus. Entretanto, ainda é um desafio para muitas culturas e, sobretudo, para os governantes que devem se basear na ciência para tomar as medidas protetivas mais eficazes, além de conscientizar a população.

Palavras-chave: Coronavirus; Infecções por Coronavirus; Epidemiologia; Delimitação das Áreas de Risco.

\begin{abstract}
COVID-19 has been a widespread disease; reaching the global pandemic scale. Its distribution was nonuniform and was modulated by several factors. In Petrolina - PE, the virus has arrived in March 2020 and showed an increasing evolution. The objective of this work is to observe how the geographical distribution of the confirmed cases of COVID-19 in Petrolina took place - period from March $23^{\text {th }}$ to July18 ${ }^{\text {th }}, 2020$. Daily monitoring analysis was done based on municipality's health department information and the Ministry of Health. We observed that this virus was introduced by people who arrived abroad in the central region of Petrolina, in March, followed by a gradual increase in confirmed cases of the disease, spreading to the most populous neighborhoods. With that, we observed the propagation is faster in populated areas and with few precautionary measures. Numerous challenges need to be overcome in the face of the new coronavirus. So far, it is known that social distance and personal protective equipment mitigate the spread of the virus. However, it is still a challenge for many cultures and, above all, for government officials who must rely on science to take the most effective protective measures, in addition to raising awareness among the population.
\end{abstract}

Keywords: Coronavirus. Coronavirus Infection. Epidemiology. Risk Areas Delimitation. 


\section{INTRODUÇÃO}

O SARS-CoV-2 é um patógeno que pertence à família do coronavírus. É o causador da doença COVID-19 e acomete principalmente a via respiratória. Essa doença possui uma alta taxa de transmissibilidade, baixa letalidade e representa uma ameaça à saúde pública ${ }^{1}$. Sua transmissão ocorre principalmente por meio de gotículas respiratórias e contato direto através de fômites, semelhante aos vírus da gripe humana, ao SarsCOV (identificado em 2002) e Mers-COV (identificado em 2012). Os sintomas clínicos mais comuns, até o momento, são febre, tosse seca, fadiga, dispneia, anosmia, ageusia ou alguma combinação destas ${ }^{2}$.

Com início em novembro de 2019, em Wuhan, na China, o surto da doença apresentou uma rápida evolução geográfica pelo mundo. No dia 30 de janeiro de 2020, tal surto foi considerado pela Organização Mundial da Saúde como uma Emergência de Saúde Pública de Importância Internacional, o mais alto nível de alerta da Organização conforme o Regulamento Sanitário Internacional, caracterizando-se como pandemia em 11 de março de $2020^{1}$.

O Brasil está inserido no movimento de globalização, com uma abrangência de conexões que o interliga com o mundo e teve seus primeiros casos notificados na época próxima ao carnaval, na qual o trânsito internacional de brasileiros fora intenso. Dessa forma, o país foi afetado pela COVID-19 tardiamente, quando comparado aos casos emergentes na Ásia e Europa e, inicialmente, acometido de maneira branda. $\mathrm{O}$ primeiro caso suspeito no Brasil foi na cidade de Minas Gerais MG em 27 de janeiro de 2020, sobre uma jovem de 22 anos que esteve em Wuhan na China no período de 29 de agosto à 24 de janeiro de $2020^{3}$. Já a primeira confirmação da doença no país ocorreu em São Paulo, em 26 de fevereiro de 2020, referente a um paciente que esteve em viagem pela Europa. O mesmo apresentava sintomas leves e foi orientado a permanecer em casa. Neste período a orientação das autoridades foi de manter as precauções com a higiene padrão, lavagem das mãos, suspensão de eventos ou atividades com aglomeração a partir 50 pessoas, isolamento da pessoa com a suspeita e acompanhar o comportamento desse então desconhecido e temeroso vírus que se expandia pelo hemisfério norte e prematuramente para o hemisfério $\mathrm{sul}^{4}$.
Há poucas evidências científicas sobre o comportamento do vírus SARS-COV-2 que apontem sua evolução perante a sazonalidade climática. Sugere-se que a prevalência deva ocorrer entre os meses de Outono e Inverno, seguindo a tendência já conhecida sobre as doenças respiratórias pré-existentes ${ }^{5,6}$.

O Brasil teve a vantagem de ter o primeiro caso suspeito com meses de atraso, porém, coincidiu com o início do outono do hemisfério sul, época na qual serve de gatilho para o aumento e propagação de doenças respiratórias ${ }^{7}$, o que pode ter contribuído para o espalhamento do novo coronavírus, porém ainda não há comprovação científica acerca da temática.

Com os primeiros casos sintomáticos importados por meio de voos internacionais, foi recomendado o isolamento em quarentena das pessoas oriundas de áreas endêmicas. Entretanto, muitos indivíduos são assintomáticos e podem assim permanecer até 14 dias sendo capazes de transmitir o vírus, mesmo sem apresentar nenhum sintoma. Esses casos assintomáticos contribuíram para a disseminação da doença das grandes cidades para o interior do país ${ }^{8}$.

O município de Petrolina, situado na mesorregião do Vale São Francisco no sertão de Pernambuco-PE, possui uma área de aproximadamente $4.562 \mathrm{~km}^{29}$. A cidade conta com inúmeros bairros, além da zona rural. Para atendêlos, podem contar com um Hospital Universitário (HU) da Universidade Federal do Vale do São Francisco (UNIVASF), de alta complexidade, com capacidade para 164 leitos sendo 14 de Unidade de Terapia Intensiva, 53 unidades de saúde entre AME e UBS e uma unidade prisional ${ }^{2,9}$.

Petrolina conta com um aeroporto, que através de conexões nacionais, realiza voos para diversas capitais do país com conexões internacionais. No município de Petrolina, o primeiro caso suspeito da doença foi registrado em 23/03/2020, em uma mulher com histórico recente de retorno da Europa $^{10}$. Desde então, vem crescendo gradativamente, mesmo com as medidas previamente adotadas pelo Ministério da Saúde e o governo do Estado. Até o dia 18/07/2020 foram registrados 1.945 casos confirmados pela doença, que até o presente momento constituía 557,1/100.000 habitantes. O Estado de Pernambuco registra um total de 78.509 casos sendo 821,5/100.000 habitantes por casos confirmados do novo coronavírus até o momento ${ }^{1}$.

Ao observar a lacuna existente sobre o novo coronavírus o SARS-COV-2, viu-se a 
Revista de Ensino, Ciência e Inovação em Saúde v.1, n. 1 (2020) 83-90

oportunidade de contribuir academicamente com a realização deste estudo. Ainda há escassas informações acerca dessa temática, que assolou todos os países em determinada proporção para cada um deles. Dessa forma, pretende-se contribuir e subsidiar as autoridades de saúde do município de Petrolina PE, com alertas sobre as áreas de maior concentração de casos da doença COVID19, a fim de auxiliar os gestores para as ações preventivas de modo que possam mitigar a propagação desse temido e desconhecido vírus.

Sendo assim, o presente estudo tem objetivo de relatar a dinâmica do espalhamento de casos confirmados, bem como sua distribuição geográfica da COVID-19 no município de Petrolina - PE, no período de 23 de março à 18 de julho de 2020, e assim subsidiar os gestores e agentes das unidades de saúde numa futura e eficaz intervenção buscando estratégias que minimizem a propagação da doença e seus efeitos deletérios através da promoção, prevenção e atenção à saúde da comunidade.

\section{MATERIAL E MÉTODOS}

Trata-se de uma pesquisa descritiva realizada com base em dados secundários dos casos confirmados da COVID-19 publicados diariamente e semanalmente pela Secretaria Municipal de
Saúde de Petrolina - PE (https://petrolina.pe.gov.br/coronavirus/coronavir us-boletins-diarios/), além dos dados epidemiológicos divulgados pelo ministério da saúde (https://covid.saude.gov.br/) e da Organização Mundial da Saúde (https://www.paho.org/pt/covid19). Os dados foram coletados no período de 20 de junho a 28 de setembro de 2020.

\section{RESULTADOS}

O início da doença no município de Petrolina - PE, ocorreu em 23 de março de 2020. A partir do primeiro caso relatado, iniciou-se uma curva crescente e gradual (Figura 1). Observou-se primeiramente uma concentração de casos na região central da cidade, região que concentra o principal centro comercial da cidade e, consequentemente, há uma grande circulação de pessoas. Casualmente, foi onde se confirmou o primeiro caso da doença na cidade: tratava-se de um paciente com histórico recente de regresso da Europa ${ }^{10}$. Observa-se que entre os 10 primeiros casos da cidade, a maioria estava localizada na região mais central e num raio de cerca de $5 \mathrm{Km}$ do primeiro caso, as quais correspondem às áreas mais populosas (Figura 1).

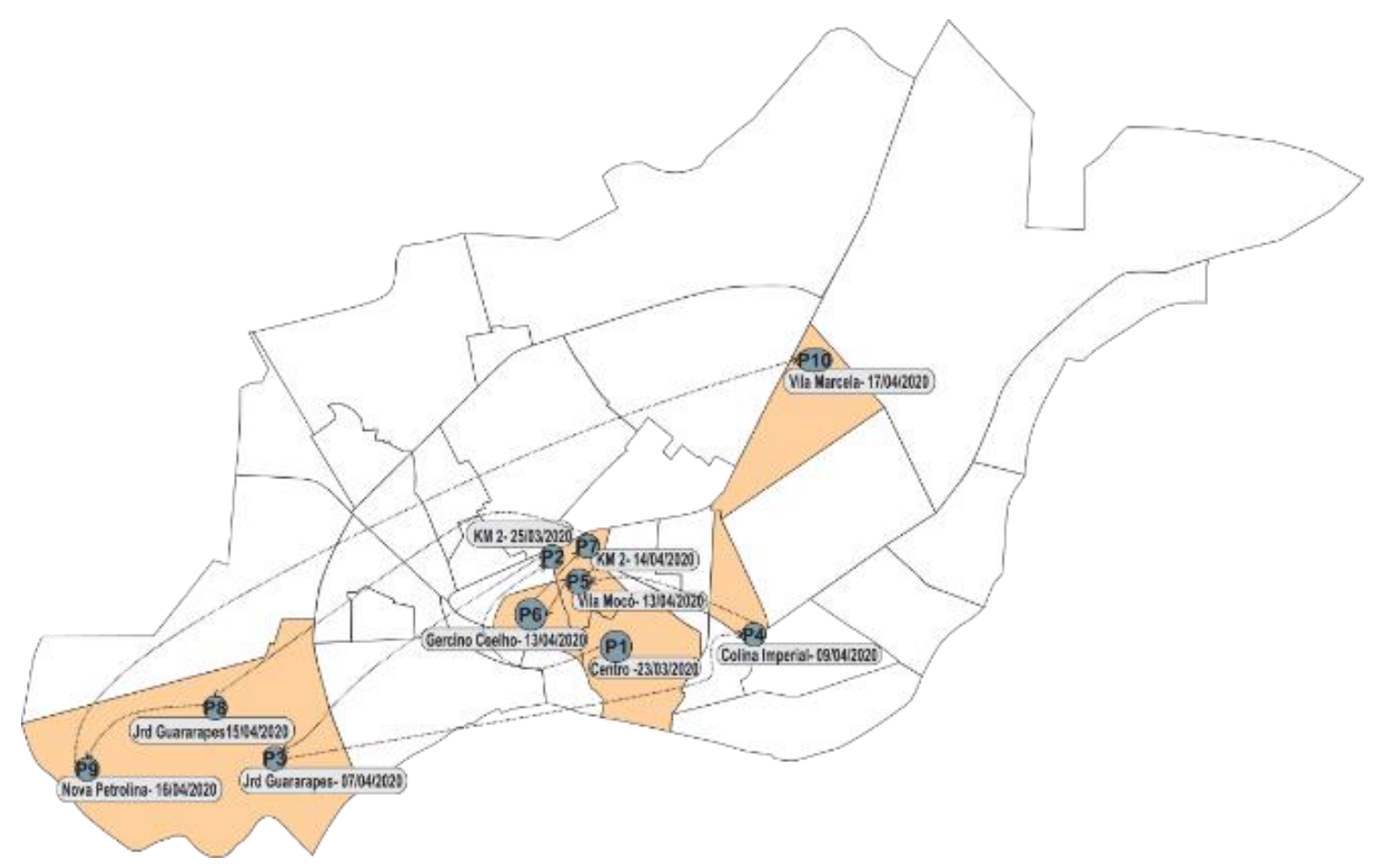

Figura 1. Localização dos 10 primeiros casos na cidade de Petrolina - PE. 
Revista de Ensino, Ciência e Inovação em Saúde v.1, n. 1 (2020) 83-90

Por duas semanas, apenas dois casos foram relatados. Entretanto, assim que se declarou a transmissão comunitária, houve um rápido aumento no número de casos (Figura 1).
Até o dia 18 de julho de 2020, haviam 1.945 casos confirmados da doença distribuídos geograficamente em quase todos os bairros, sendo 97 na área urbana e 26 na zona rural do município (Figura 2).

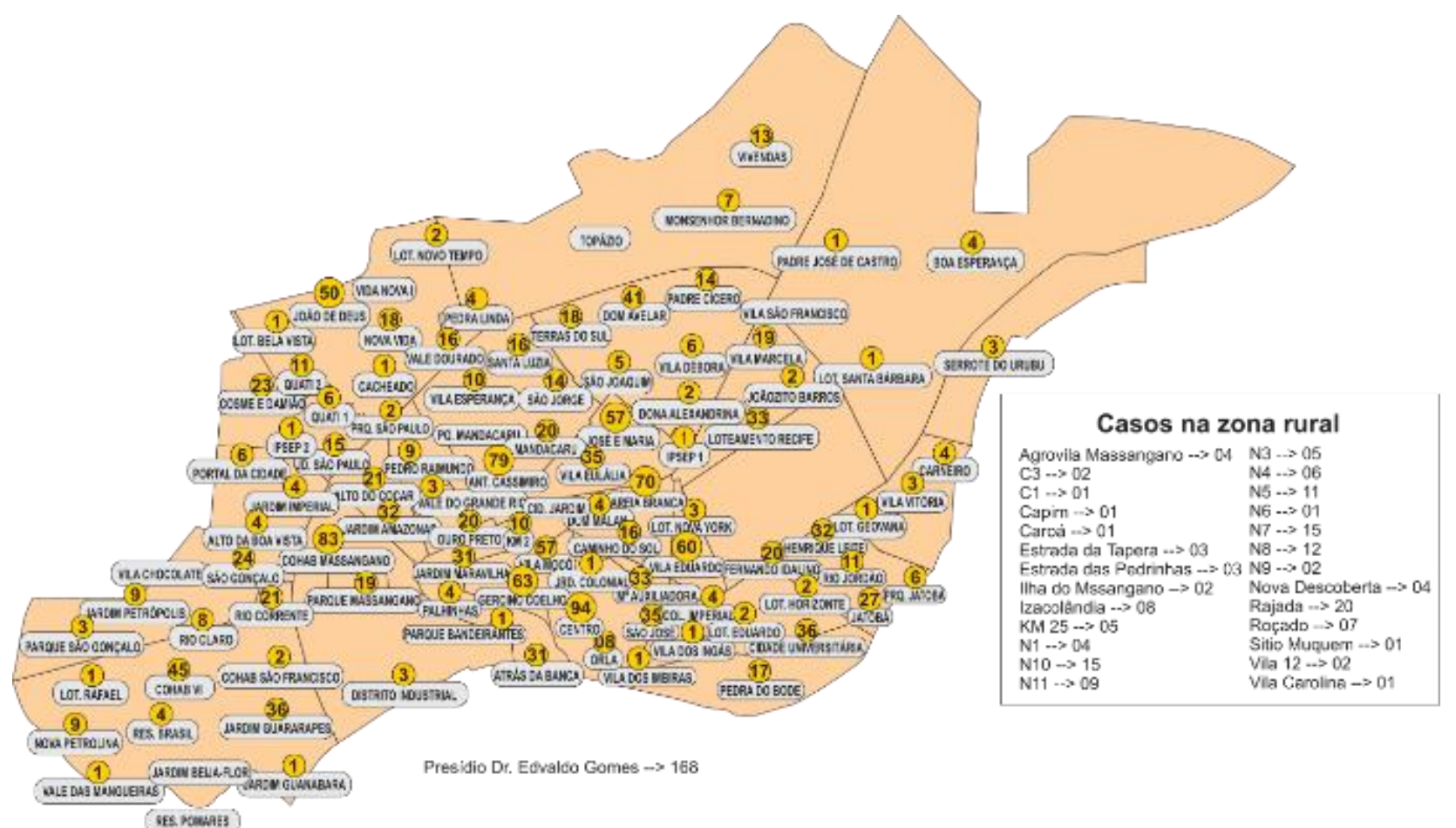

2020

Figura 2. Distribuição dos casos de COVID-19 na cidade de Petrolina relatados até 18 de Julho de

Foi observada uma maior concentração de casos confirmados do novo coronavírus nos bairros Centro (94 casos); Cohab Massangano (83 casos); Areia Branca (70 casos) e no presídio municipal que apresentava 168 casos no período do estudo (Figura 3).

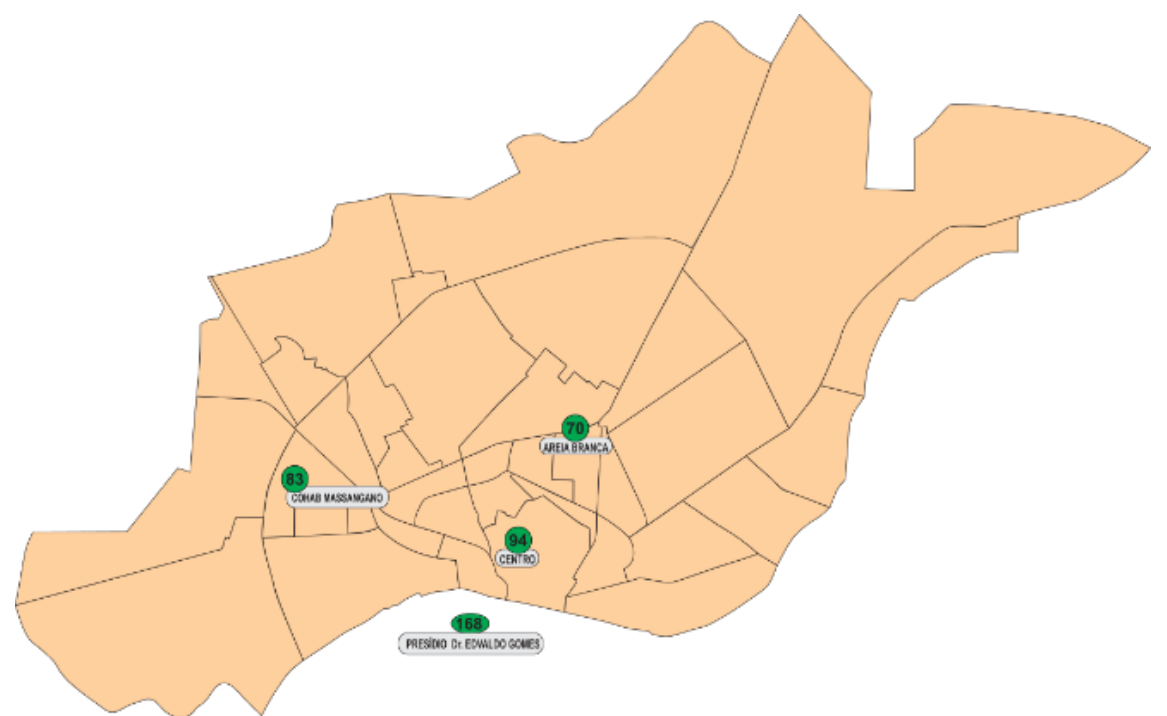

Figura 3. Destaque dos bairros mais afetados pela COVID-19 em Petrolina - PE. 
$-$

No Brasil, o número de casos manteve-se em constante aumento. Mostrando que o espalhamento da doença tem progredido paulatinamente (Figura 4A). Já em Pernambuco, podemos observar que a doença atingiu rapidamente números bem altos, o que levou a um caos no sistema de saúde local, principalmente na capital $^{11}$ e logo após, atingiu um certo platô, com pequenas altas (Figura 4B). Já em Petrolina, o comportamento da doença foi ligeiramente diferente. Iniciou-se mais tardiamente, observamos poucos casos confirmados nos primeiros meses e uma disseminação meio constante de cerca de 40 novos casos diários. Até o mês de julho, quando ocorreu a abertura do comércio local e houve um aumento exponencial no número de novos casos (Figura 4C).
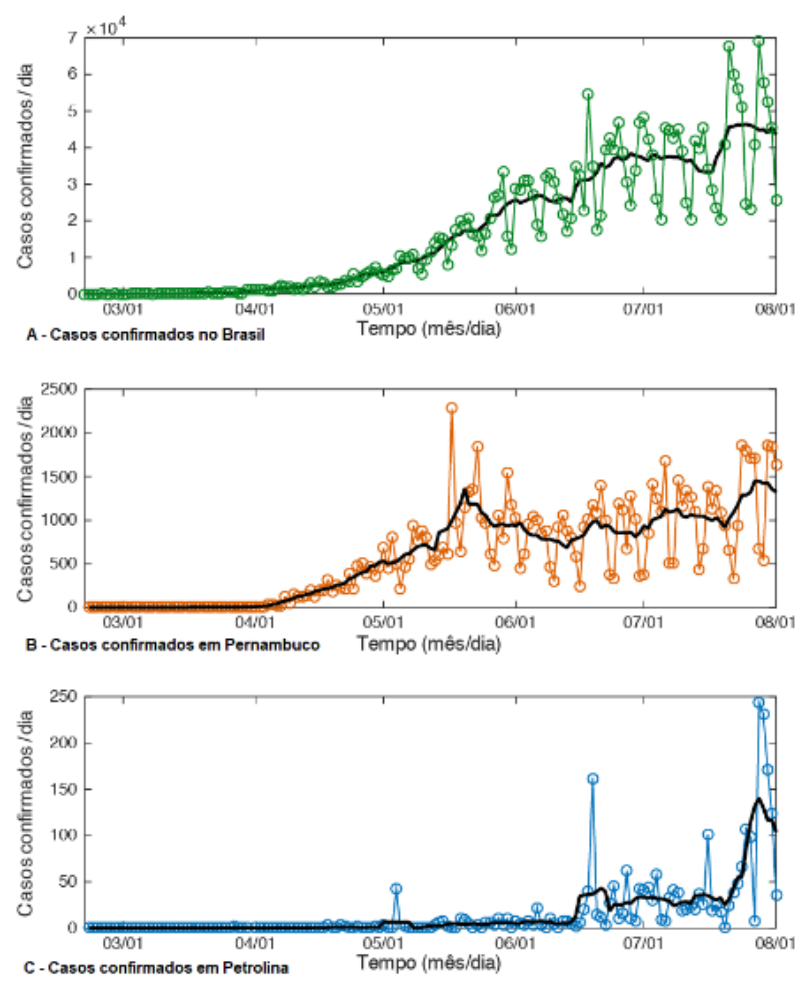

Figura 4. Curva de casos confirmados diariamente de indivíduos infectados pelo novo coronavírus. Os gráficos representam os casos reportados no Brasil (A), em Pernambuco (B) e em Petrolina $(\mathrm{C})$, respectivamente de cima para baixo. As linhas coloridas representadas nas figuras A, B e $\mathrm{C}$ referem-se aos números diários absolutos e as linhas na cor preta representam a média móvel de 07 dias.

\section{DISCUSSÃO}

O cenário do novo coronavírus no Brasil, assim como no município de Petrolina - PE, ainda é uma incógnita que necessita de maior elucidação com o auxílio da ciência, como pesquisas para maiores informações acerca do vírus, testagem em massa da população, dos casos suspeitos e não só dos que chegam nas unidades de saúde, além de maior precisão nas notificações. São necessários mais trabalhos científicos sobre o tema para que se fortaleçam as bases da informação no intuito de auxiliar os gestores na tomada de decisão mais precisa e eficaz.

Os primeiros casos notificados de infecção pelo novo coronavírus no estado de Pernambuco, ocorreram juntamente com o de outros estados do Nordeste, ainda no mês de março. Petrolina também seguiu esse padrão. $\mathrm{O}$ diferencial foi que na cidade houve o isolamento dos primeiros casos, o que ajudou no controle inicial da infecção (Figura 1).Com isso, houve um atraso na elevação dessa curva em Petrolina, quando comparado com outras realidades a exemplo do estado ao qual pertence, Pernambuco, e outros estados nordestinos. ${ }^{12}$

Autores relatam sobre as diferentes formas pela qual certos estados do Nordeste foram atingidos pelo novo coronavírus, levando em consideração principalmente $o$ índice de desenvolvimento humano (IDH). Embora o estado de Pernambuco tenha um nível de IDH um pouco mais elevado em relação a outros estados como Sergipe, Alagoas, Bahia e Maranhão, o estado apresenta uma alta incidência de casos e maior taxa de mortalidade registradas pela COVID-19. Ainda assim, foi um dos estados cuja atitude quanto às medidas de isolamento foi mais rápida, com apenas dois dias, entre a notificação do primeiro caso e as medidas de contenção ${ }^{12}$.

Em Petrolina, ocorreu o fechamento precoce dos estabelecimentos comerciais, restaurantes e escolas, conforme o decreto estadual $48.834 / 2020$, do dia 20 de março de 2020. Este decreto foi suspenso 10 semanas depois e, em 01 de junho, quando as atividades foram retomadas com a execução de algumas medidas de segurança ${ }^{13}$. Entretanto, com o aumento no número de casos e a redução no número de leitos disponíveis para os casos graves, o comércio voltou a fechar em 13 de julho, e foi reaberto em 14 dias, após a desocupação dos leitos disponíveis para o atendimento da COVID-19 ${ }^{14}$. 
Ademais, a cidade contou com estratégias na área de saúde para enfrentamento da doença: um hospital de campanha foi inaugurado em 25 de maio e, ao fim de 1 mês de funcionamento, foi responsável por atender 31 pacientes sem atingir $10 \%$ da sua capacidade de internação ${ }^{15}$.

Além do enfrentamento da COVID-19, o município hoje conta com um Hospital que é referência para assistência à saúde às vítimas de trauma para mais 53 municípios do sertão pernambucano, num raio de $400 \mathrm{~km}$ de Petrolina. Este hospital tem 20 leitos de terapia intensiva adaptados para receber pacientes com diagnóstico de COVID-19 ${ }^{16}$. Outrossim, hospitais da rede particular também passaram a receber pacientes com o novo coronavírus.

Até meados de julho, percebeu-se que as áreas com maior concentração dos casos do novo coronavírus (Figura 3) chamam atenção por serem áreas com grande número de caixas de endereçamento postal, assim podemos inferir que possuem maior aglomerado de pessoas ${ }^{9}$.

Esse espalhamento da infecção por SARSCoV-2 poderia ser evitado monitorando os pacientes, mesmo os assintomáticos que vieram de viagem, e assim mitigar a propagação da doença. $\mathrm{Na}$ província de Heilongjiang, na China, houve o rápido contágio do vírus entre moradores de um mesmo edifício. Ao serem atendidos no mesmo hospital, foi identificado que a origem provável deste cluster tenha sido um indivíduo assintomático, oriundo de viagem internacional. Dessa forma, pacientes com diagnóstico confirmado para COVID-19, mesmo assintomáticos, devem ser bem orientados quanto a forma de isolamento bem como medidas contínuas 1 . de higiene e rastreio de indivíduos assintomáticos a fim de evitar o contágio ${ }^{17}$.

Diversas questões podem ser levantadas
quanto àresponsabilidade popular ao enfrentamento da pandemia. Acredita-se que a 2 . população tenha chegado a um estado coletivo que vem sendo nomeado como "fadiga da quarentena"18. Em Petrolina, tal realidade também se mostra presente e pode ter interferido no desenvolvimento da pandemia na cidade. O poder público tem recebido diversas denúncias sobre 3. descumprimento das medidas restritivas em toda a cidade $^{19}$. Com a soma desses diversos fatores, dentre eles os desafios das restrições, da notificação de casos, de acesso a exames diagnósticos, aos serviços de saúde, em especial à 4 . população mais vulnerável, torna-se ainda mais complexo o enfrentamento deste novo vírus para os gestores de saúde do município e região, que seguem as medidas adotadas pelo Ministério da Saúde e governo do Estado ${ }^{4,20}$.

É necessário que as autoridades nacionais e internacionais de vigilância epidemiológica possuam informações verídicas e realistas, fornecidas pelos pesquisadores especializados, para que os dados sejam da melhor qualidade e reconheçam a importância de se fomentar a pesquisa acerca dos temas de saúde ${ }^{21}$.

\section{CONCLUSÃO}

O presente estudo possibilitou observar a chegada da COVID-19 no município de PetrolinaPE, o qual provavelmente foi importado de outro país e rapidamente se propagou entre os bairros da cidade, nos locais com maior número de pessoas onde vemos um limite restrito de distanciamento entre os indivíduos.

Dessa forma, é possível subsidiar as autoridades de vigilância em saúde a trabalhar com foco no tocante desta desconhecida afecção, que haja vista tornou-se um problema de saúde pública e assim, propor junto as unidades de saúde alertas de educação em medidas de precaução, e atenuar os danos deste novo coronavírus.

O enfrentamento ao novo vírus ainda é incerto e depende de inúmeros fatores. O Brasil tem capacidade para superar esse desafio, pois o SUS é um dos melhores sistemas públicos de saúde do mundo, para isso é preciso um intenso esforço governamental além, claro, da mobilização social.

\section{REFERÊNCIAS}

1. OPAS/OMS | Organização Pan-Americana da Saúde [Internet]. Folha informativa COVID-19 Escritório da OPAS e da OMS no Brasil [acesso em 28 set 2020]. Disponível em: https://www.paho.org/pt/covid19

2. Werneck GL, Carvalho MS. A pandemia de COVID-19 no Brasil: Crônica de uma crise sanitária anunciada. Cadernos de Saúde Pública; 36 (5): e0068820. https://doi.org/10.1590/0102-311x00068820

3. Ministério da Saúde (BR). Secretaria de Vigilância em Saúde. Infecção Humana pelo Novo Coronavírus (2019-nCoV). Brasília: Ministério da Saúde; 2020.

4. Brasil. Ministério da Saúde.Portaria ${ }^{\circ} 188$, de fevereiro de 2020. Declara Emergência em Saúde Pública de importância Nacional (ESPIN) em 
decorrência da Infecção Humana pelo novo Coronavírus (2019-nCoV). Diário Oficial da União, Brasília (DF) 2020 fev 04; Seção 1:1.

5. 5. Nobre AFS, Sousa RCM, Santos MC dos, et al. Primeira detecção de coronavírus humano associado à infecção respiratória aguda na Região Norte do Brasil. Rev Pan-Amazônica Saúde. 2014 Jun;5(2):37-41. http://dx.doi.org/10.5123/S2176$\underline{62232014000200005}$

6. Ministério da Saúde (BR). Secretaria de 13. Vigilância em Saúde. Boletim epidemiológico especial - Doença pelo coronavírus COVID19. Brasília: Ministério da Saúde; 2020.

7. Martins AC [Internet]. Doenças respiratórias de outono preocupam mais com pandemia [acesso em 28 set 2020]. Disponível em: https://www.jornalcruzeiro.com.br/sorocaba/doen 14 . cas-respiratorias-de-outono-preocupam-maiscom-pandemia/

8. Duarte R [Internet]. Covid-19: a contínua importância de detectar os assintomáticos [acesso em 11 out 2020]. Disponível em: https://pebmed.com.br/covid-19-a-continuaimportancia-de-detectar-os-assintomaticos/

9. Instituto Brasileiro de Geografia e Estatística [Internet]. Pernambuco | Petrolina | Panorama [acesso em 28 set 2020]. Disponível em: https://cidades.ibge.gov.br/brasil/pe/petrolina/pan orama.

10. Prefeitura municipal de Petrolina [Internet]. Coronavírus Boletins Diários | Prefeitura Municipal de Petrolina [acesso em 28 set 2020]. Disponível em: https://petrolina.pe.gov.br/coronavirus/coronaviru s-boletins-diarios/

11. Marco Zero [Internet]. Profissionais da saúde já falam em colapso da rede de atendimento às vítimas da Covid-19 em Pernambuco [acesso em 18. 16 out 2020]. Disponível em: https://marcozero.org/profissionais-da-saude-jafalam-em-colapso-da-rede-de-atendimento-asvitimas-da-covid-19-em-pernambuco/

12. Kerr L, Kendall C, da Silva AAM, et al. COVID-19 in northeast Brazil: Achievements and limitations in the responses of the state 19. governments. Cienc e Saude Coletiva.
2020;25:4099-120. https://doi.org/10.1590/1413$\underline{812320202510.2 .28642020}$

13. Pernambuco. Poder executivo. Decreto do Executivo $\mathrm{n}^{\circ} 48$ 834/2020. Define no âmbito socioeconômico medidas restritivas temporárias adicionais para enfrentamento da emergência de saúde pública de importância internacional decorrente do coronavírus. Diário Oficial do Estado, Recife (PE), 2020 mar 20; Seção 2:1.

14. Prefeitura Municipal de Petrolina [Internet]. Prefeitura decreta novo isolamento social a partir da próxima segunda-feira [acesso em 28 set 2020]. Disponível em: https://petrolina.pe.gov.br/prefeitura-decretanovo-isolamento-social-a-partir-da-proximasegunda-feira/

14. 15. Prefeitura Municipal de Petrolina [Internet]. Hospital de campanha completa um mês com 31 pacientes atendidos [acesso em 28 set 2020]. Disponível em: https://petrolina.pe.gov.br/hospital-de-campanhacompleta-um-mes-com-31-pacientes-atendidos/

15. 16. EBSERH [Internet]. Ebserh estrutura e amplia assistência de alta complexidade em Covid-19 [acesso em 28 set 2020]. Disponível em: http://www2.ebserh.gov.br/web/huunivasf/noticias//asset_publisher/JYdUOrTtibKl/content/id/55448 53

16. 17. Liu J, Huang J, Xiang D. Large SARS-CoV-2 outbreak caused by asymptomatic traveler, China. Emerg Infect Dis;26(9):2260-3. https://doi.org/10.1056/NEJMoa2001017

17. 18. Cremepe [Internet]. A fase de fadiga da quarentena [acesso em 28 set 2020]. Disponível em: http://www.cremepe.org.br/2020/06/29/afase-de-fadiga-da-quarentena/

19. Prefeitura municipal de Petrolina [Internet]. Ouvidoria registra quase 6 mil denúncias de descumprimento de medidas restritivas [acesso em 5 out 2020]. Disponível em: https://petrolina.pe.gov.br/ouvidoria-registraquase-6-mil-denuncias-de-descumprimento-demedidas-restritivas/

20. de Souza WM, Buss LF, Candido D da S, et al. Epidemiological and clinical characteristics of the COVID-19 epidemic in Brazil. Nat Hum Behav; 
Revista de Ensino, Ciência e Inovação em Saúde v.1, n. 1 (2020) 83-90

4(8):856-65. https://doi.org/10.1038/s41562-020$\underline{0928-4}$
21. Freitas ARR, Napimoga M, Donalisio MR. Análise da gravidade da pandemia de Covid-19. Epidemiologia e Serviços Saúde; 29(2): e2020119. https://doi.org/10.5123/s1679-

49742020000200008 